\section{Knowledge of multidrug-resistant} tuberculosis in the Thabo Mofutsanyana District, Free State, South Africa: A Grade 10 leariner's project

To the Editor: Tuberculosis (TB) remains one of the leading causes of mortality in the world. ${ }^{[1]}$ South Africa (SA) has the third highest incidence of TB, largely fuelled by the HIV epidemic and poor TB management. ${ }^{[1-3]}$ The incidence of multidrug-resistant (MDR)-TB is also increasing, with SA among the five countries contributing to $60 \%$ of new cases. ${ }^{[4]}$ The reported number of deaths in SA due to MDR-TB has increased by $16.6 \%$ between 2013 and 2014..$^{[2]}$

Thabo Mofutsanyana District, a rural area in the Free State Province, has one of the highest provincial TB death rates $(9.3 \%) .{ }^{[2]}$ The learner's hypothesis was that the people in the Thabo Mofutsanyana District have limited knowledge of TB and MDR-TB, which could relate to the high disease burden and defaulter rate. A questionnaire to test the knowledge of MDR-TB was designed and translated to all local languages in the area. The questionnaire was distributed to high school learners at five district schools as well as to nursing personnel working at the local clinics and hospitals. Of the 550 questionnaires handed out, 500 were returned and analysed (response rate of 90.9\%). Learners accounted for $57.2 \%$ of the participants. The results showed that $67.2 \%$ of people in the district had no knowledge of MDR-TB. Possible reasons given were lack of posters, posters not in their local language, illiteracy, and not being informed by healthcare facilities. Participants with knowledge of MDR-TB indicated that they gained information from local clinics (45.7\%), the media (33.5\%) and other sources including family members, friends and schools (20.7\%). Only $44.5 \%$ of the knowledgeable participants knew that the duration of MDR-TB treatment is 24 months. It was encouraging to see that $93.3 \%$ of the knowledgeable participants knew the main symptoms of MDR-TB. With the results showing a severe lack of knowledge in an area with a high TB burden, the learner designed and produced pamphlets with information on TB and MDR-TB and distributed these to schools and clinics in the district. The pamphlets included a list of TB symptoms and an explanation of TB, stating that it is curable. Furthermore, she organised workshops to educate people. To reach the youth, she initiated a project on social media, by successfully distributing information via Instagram and other social media platforms.

\section{Lerato Ntsutle}

Grade 10 learner, Witteberg High School, Bethlehem, Dihlabeng District, Free State, South Africa

\section{Nathaniel Mofolo}

Head of Department: Family Medicine, Faculty of Health Sciences, University of the Free State, Bloemfontein, South Africa mofolon@ufs.ac.za

1. World Health Organization. World Health Statistics 2011. Geneva: World Health Organization, 2011. http://www.who.int/gho/publications/world_health_statistics/EN_WHS2011_Full.pdf?ua=1 (accessed 6 April 2016).

2. Statistics South Africa. Mortality and Causes of Death in South Africa, 2014: Findings from Death Notification. Pretoria: Statistics South Africa, 2015. http://www.statssa.gov.za/publications/P03093/ P030932014.pdf (accessed 06 April 2016).

3. National Department of Health, South Africa. National Strategic Plan on HIV, STIs and TB, 2012 - 2016 Pretoria: DoH, 2011. http://www.gov.za/sites/www.gov.za/files/national\%20strategic\%20plan\%20on\%20 hiv\%20stis\%20and\%20tb_0.pdf (accessed 06 April 2016).

4. National Department of Health, South Africa. Multi-drug Resistant Tuberculosis: A Policy Framework on Decentralised and Deinstitutionalised Management for South Africa. Pretoria: DoH, 2011. http:// www.tbfacts.org/wp-content/uploads/2015/08/SA-MDR-TB-Policy.pdf (accessed 06 April 2016).

S Afr Med J 2016;106(7):648. DOI:10.7196/SAMJ.2016v106i7.10882 